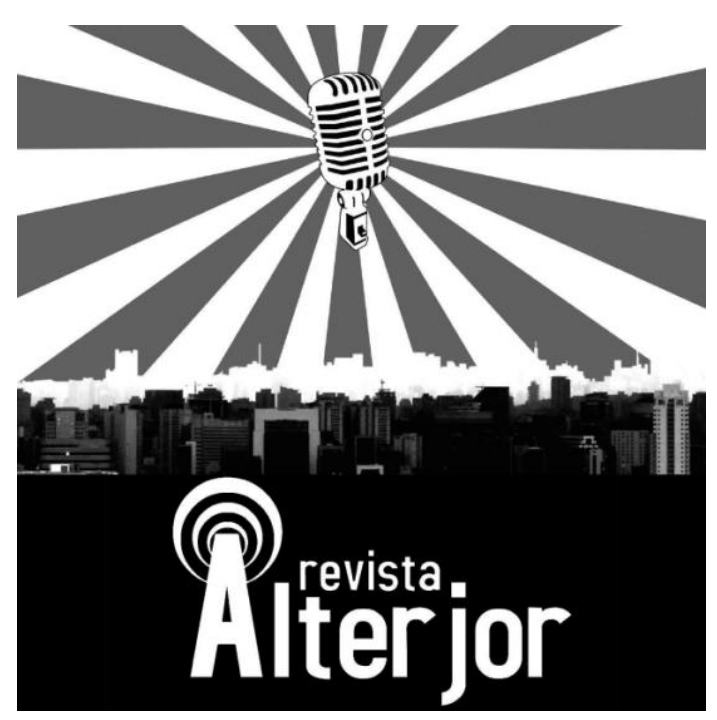

DOSSIê: "Comunicação nas Periferias"

\title{
SONIA VIRGINIA MOREIRA E AS GEOGRAFIAS DA COMUNICAÇÃO
}

\author{
Mara Rovida Martini ${ }^{1}$ \\ Edgard Patrício ${ }^{2}$
}

RESUMO: No $10^{\circ}$ aniversário do Grupo de Pesquisa da Intercom Geografias da Comunicação, foi feito um levantamento sobre a produção acadêmica na interface comunicação e geografia. Os dados observados dão o gancho para a entrevista com a professora doutora Sonia Virginia Moreira, umas das criadoras do GP.

PALAVRAS-CHAVE: Comunicação. Geografia. Entrevista.

ABSTRACT: In Geographies of Communication Research Group (Intercom) 10th birthday, a survey of academic production in the interface Communication and Geography was registered. This data is a starting for the dialogue with Sonia Virginia Moreira, one of the Geographies Communication Group founders.

KEYWORDS: Communication. Geography. Interview.

\footnotetext{
${ }^{1}$ Doutora em Ciências da Comunicação pela ECA-USP, docente do Programa de Pós-graduação em Comunicação e Cultura da Universidade de Sorocaba (PPGCC-Uniso) e jornalista. E-mail: mara.rovida@prof.uniso.br.

2 Jornalista. Doutor em Educação pela UFC, docente do Curso de Jornalismo e do Programa de Pósgraduação em Comunicação da Universidade Federal do Ceará (PPGCOM/UFC). E-mail: Edgard@ufc.br.
}

Revista ALTERJOR

Grupo de Estudos Alterjor: Jornalismo Popular e Alternativo (ECA-USP)

Ano 10 Volume Ol Edição 23 Janeiro-Julho de 202l

Avenida Professor Lúcio Martins Rodrig̉ues, 443, Cidade Universitária, São Paulo, CEP: 05508-020 


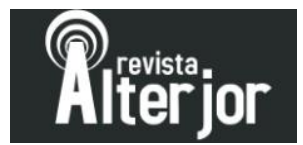

\section{INTRODUÇÃO}

A pesquisa em Comunicação sempre foi tributária da interdisciplinaridade. Os ‘flertes' são históricos e explícitos com a Sociologia, Filosofia, Psicologia, Linguística, História e até com a Estatística, ora vejam só! Sonia Virginia Moreira, nessa entrevista, concedida em novembro de 2020, chama atenção para um campo de conhecimento que andou meio arredio em relação ao pareamento com a pesquisa em Comunicação. Ela fala da Geografia, que, no Brasil, começa essa aproximação, com mais força, a partir da criação do grupo de pesquisa Geografias da Comunicação, há 11 anos, no âmbito da Sociedade Brasileira de Estudos Interdisciplinares da Comunicação (Intercom). Frente a uma sociedade que se 'espraia' em inter-relações e complexidades a partir do digital, a Geografia ancora essa ampliação trazendo aportes que possibilitam mediar a compreensão de conceitos como lugar, espaço, território, fronteira, local, bordas, periferia. A simpatia e generosidade estruturais de Sonia atravessaram toda a prosa, e facilitaram o trabalho dos entrevistadores. Que os leitores tenham o mesmo prazer ao ler a entrevista que tivemos, ao passar quase três boas horas em companhia de Sonia.

\section{ENTREVISTA}

Mara e Edgard: O grupo de pesquisa da Intercom Geografias da Comunicação completou 10 anos em 2019. Vocês publicaram um livro (MOREIRA et al, 2019) com um balanço dessa produção ou, como indicado no título da obra, um registro do percurso dos estudos. Quais são os destaques dessa década de trabalho e de que forma podemos conectá-los a sua pesquisa no período?

Sonia: Eu acho que é bacana dizer por onde o grupo andou nesse período. A questão urbana sempre foi um tema bastante presente no grupo das Geografias, e os diversos usos, digamos assim, das cidades. Eu, particularmente, achava que região seria o tema mais frequente, mas não foi. Cidades, regiões, espaço, algumas questões de fronteiras, que também acho ser uma coisa bem interessante no grupo, foram os temas trabalhados com maior frequência nesses dez anos de apresentações de trabalho. Nesse período, foram apresentados 189 textos, sendo 22 sobre cidades; 20 sobre região; 18 sobre 


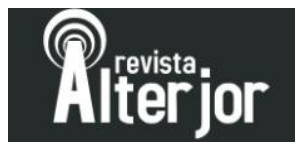

fronteiras; e, em quarto lugar, 17 sobre territórios. A ideia de territórios também contempla espaço digital e espaço local. Eu penso que, de uma maneira geral, isso dá uma dimensão sobre os interesses dos pesquisadores e, eu acho, também das conexões que os textos vão fazendo entre o campo da Geografia e o da Comunicação. Então você está falando de Comunicação nestes contextos: cidade, região, fronteiras, territórios, espaço digital e local, que eu acredito que tem tudo a ver com a nossa conversa também.

Mara e Edgard: Por curiosidade, Sonia, aparece "periferia" ou "periferias" alguma vez?

Sonia: Não especificamente. As cidades aparecem muito mais como "experiências urbanas" como, por exemplo, a música. Nós somos, como você é também, Mara, e acho que também o Edgard, muito influenciados pela escrita do Milton Santos. E o Milton Santos cujo último livro data de 2001, "Territórios e Sociedade do século XX" (SANTOS; SILVEIRA, 2001), foi escrito com a Maria Laura Silveira. O livro não tem uma divisão, o que é muito bonito; é um livro efetivamente escrito a quatro mãos. E ele trabalha bastante com essa questão dos centros urbanos como espaço de rapidez em contraste com os espaços de lentidão. Então acho que é muito mais nesse sentido do urbano; essas características da cidade como espaço.

Mara e Edgard: E as questões regionais, as divisões entre Sul, Sudeste, Nordeste, por exemplo, estão presentes? Isso aparece nesse levantamento da produção do grupo?

Sonia: Estou falando no sentido literal, sem uma precisão mesmo. Do que eu tenho desses dez anos: muito cidade, muito metrópole (a cidade metrópole) e, dentro da metrópole, os contrastes. Muito mais por aí. Acho que seriam duas coisas: de contrastes e de possibilidades que a metrópole pode te oferecer.

Mara e Edgard: O que veio antes do GP? Qual a caminhada desse grupo de pesquisadores ou sua para chegar nesse espaço do grupo?

\footnotetext{
Revista ALTERJOR

Grupo de Estudos Alterior:Jornalismo Popular e Alternativo (ECA-USP)

Ano 10 Volume ol Edição $23 \quad$ Janeiro-Junho de 2021

Avenida Professor Lúcio Martins Rodriģues, 443, Cidade Universitária, São Paulo, CEP: 05508-020
} 
Sonia: Olha, eu acho que o GP é indutor a partir do momento em que ele existe. Ele é indutor da produção de textos que tenham a ver com esses elementos da Geografia, como a questão do território ou a questão do regional. Mas você já tinha pesquisadores no Brasil trabalhando com o tema. Por exemplo, você tinha o pessoal trabalhando com fronteiras. Primeiro no Rio Grande do Sul, aliás eu acho que em outros estados do Sul de maneira geral. A própria Roberta Brandalise, que é a atual coordenadora do GP, defendeu uma tese de doutorado sobre TV na fronteira Brasil - Uruguai. Isso implica a questão da cultura. Inclui pensar na comunicação nessas bordas, nessas cidades, principalmente, nas cidades gênesis que têm essas linhas, às vezes invisíveis, para compreender como é que vai acontecer essa troca de culturas e como se observa a mistura de identidades. A gente tinha professores que já trabalhavam nisso. E depois do Sul veio o Centro-Oeste, porque tem aquela região do Paraguai e da Bolívia, principalmente Paraguai, que tem de um lado Ponta Porã e do outro Pedro Juan, conectadas por uma avenida. Você está lá e cá o tempo todo. E a cultura do Paraguai é muito forte também lá no Sul. Então eu acho que isso já era um tema que se apresentava com os pesquisadores da região. Então a gente volta para aquele outro elemento da Geografia que é a região. De alguma maneira, dependendo da sua região, há um estímulo para a produção de textos ou para a colaboração de pesquisas que tenham a ver com a temática das Geografias da Comunicação. Só para finalizar, quando o grupo é formado, ele acaba sendo, então, um indutor de outros tipos de pesquisa. Eu tive a sorte de estar no momento de criação de dois GPs, o de Rádio, lá atrás com a Doris Haussen, e esse, de Geografias da Comunicação, com Anamaria Fadul, porque ela me apresentou e me falou do livro Geographies of Communication (FALKHEIMER; JANSSON, 2006). Esse livro foi fundamental, foi uma luz, porque inclui também a comunicação no mundo digital.

Mara e Edgard: Aproveitando essa questão do mundo digital - que também está muito presente agora nas discussões das periferias, dessa produção comunicacional fora dos espaços mais centrais justamente por conta da pandemia -, como é que você está vendo 


\section{Aireior}

o impacto do digital nessas discussões, nessas realidades que vão aparecendo nas pesquisas que são apresentadas no GP?

Sonia: (Antes que eu esqueça, Innis (2011; 2008; 2007) e Falkheimer (2006) são dois autores que é um absurdo não dizer os nomes. São os dois também que ajudaram muito a me inspirar.)

O mundo digital é uma coisa fantástica porque promove, efetivamente, essa possibilidade de produção. Eu acho que isso é o mais interessante. Recepção, eu tenho lá as minhas dúvidas. Trabalhando num projeto, desde 2018, com a Nélia Del Bianco e o Cézar Franco Martins - que foi meu bolsista de iniciação científica lá na Universidade Federal de Juiz de Fora e hoje em dia é mestrando; sou orientadora dele - nós três observamos muito esse universo das regiões de sombra e de silêncio, porque quando a gente vai falar de periferias - sem falar de periferias, acho que falar da própria questão das metrópoles e os lugares distantes -, a gente tem lugares de sombra e de silêncio. Então, acho que nós temos uma produção muito forte, mas sobre a recepção há alguma dúvida do tipo de alcance que essa comunicação tem. Você, Mara, na apresentação do seu livro (ROVIDA, 2020) fala disso, da dificuldade de quem faz esse jornalismo das periferias em chegar naquela comunidade, que é a comunidade deles, onde estão inseridos. O público está muito mais fora do que dentro. Só para fazer um link com essa questão das regiões de sombra e de silêncio. A gente fala sombra e silêncio porque no fundo está trabalhando com telecomunicações, isto é, esse mundo digital implica os tipos de acesso que você tem, se você tem banda larga ou não; mas também se trabalha com a mídia TV e a mídia Rádio.

Assim, no geral, respondendo à pergunta, eu acho que o digital traz essa facilidade para todo mundo, inclusive para quem mora num grande centro e que tem acesso a essa infraestrutura. Porque acho que nós não podemos nunca deixar de lado isso: tudo bem, você pode produzir, mas para produzir você tem que ter infraestrutura. E infraestrutura no Brasil é um problema ainda. E a questão da infraestrutura é básica. E esse projeto [com a Nélia Del Bianco e o Cézar Franco Martins] trabalha muito com isso porque eu acho que, no campo da comunicação, nós ainda falamos pouco da infraestrutura 


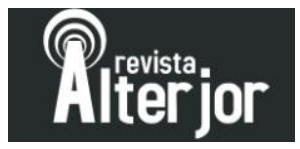

existente. Acho que trabalhamos muito com o mundo ideal, até mesmo na torcida de que aquele mundo efetivamente exista. Mas o real ainda é complicado para nós.

Mara e Edgard: Pensando na questão da infraestrutura, você acha que agora, com a experiência da pandemia, isso deve aparecer para o campo da pesquisa na comunicação como um item central?

Sonia: Quando a pandemia chegou, esse dado se mostrou muito relevante. O que a gente viu que aconteceu na pandemia? O rádio se revelou como o grande meio difusor. Os alunos estão tendo aula pelo rádio. Eu vi uma, depois a segunda matéria, a terceira, então comecei a registrar. Eram duas coisas recorrentes, a foto [nas reportagens] do rádio - geralmente, nos lugares mais distantes -, e o celular - nos grandes centros. Então você tem dois aparatos ali, dois equipamentos que eu acho que foram muito presentes nesse primeiro momento da pandemia. Tem uma imagem desse período bem interessante: uma mãe, com os três filhos, e o celularzinho dela em cima da mesa e eles tendo aula pelo celular, porque só ela tinha celular na família. Teve também o pai que denunciou a falta de sinal de rádio para o filho ter aula. Então, ele fez uma cabaninha, porque precisava proteger do sol e da chuva, num lugar onde dava para sintonizar e o filho ficava lá, tendo aula. Então eu acho que a pandemia tornou evidente a infraestrutura que a gente tem. E essa infraestrutura quando existe é paga? Quanto custa? Quem são os grandes, os principais fornecedores de infraestrutura hoje de banda larga no Brasil?

Sairá no ano que vem (2021) um artigo sobre os pequenos provedores de internet. Isso é super-relevante hoje no Brasil, porque eles estão alterando completamente esse mercado que antes era dominado só pelos grandes grupos. E a fibra ótica facilita também. Então, você tem a fibra ótica como uma infraestrutura tecnológica e real no Brasil, e junto com ela tem os pequenos provedores que vêm fornecer essa possibilidade de as pessoas terem acesso à internet e à banda larga.

Revista ALTERJOR

Grupo de Estudos Alterjor:Jornalismo Popular e Alternativo (ECA-USP)

Ano 10 Volume Ol Edição 23 Janeiro-Junho de 202l

Avenida Professor Lúcio Martins Rodrig̉ues, 443, Cidade Universitária, São Paulo, CEP: 05508-020 


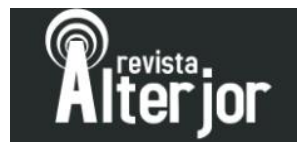

Mara e Edgard: Essa questão do digital também traz um outro dado que tem a ver com o controle (ou a falta dele) e a centralização dos serviços das big techs. Como fica essa correlação entre direcionar a produção comunicacional para esse território digital - por conta da facilidade da distribuição e da diminuição dos custos de produção - e o controle sobre a recepção? Isso porque, na produção comunicacional, tem-se um público presumido e nessa forma de distribuição não se tem garantias de quem irá consumir essa produção, nem como e nem onde.

Sonia Virginia Moreira: Isso já acontecia antes do digital. A gente volta para o rádio. O rádio sempre foi um meio de comunicação muito local, sendo essa uma de suas principais características. O rádio tem essa questão da proximidade como uma coisa muito forte. Mas, pensa bem, no rádio AM, quando você produzia um material num lugar, numa cidade, depois ele se propagava por ondas e chegava no Brasil inteiro. Por exemplo, o Luiz Carlos Saroldi fazia um programa, chamado Noturno, de música popular brasileira e o Brasil inteiro ouvia. E ele era tipicamente um programa musical de MPB, carioca, em uma emissora carioca, a JB [Jornal do Brasil]. Então ele tinha essa característica local. Eu acho que no digital, o que é mais evidente - e que talvez mais impressiona a gente - é a velocidade e as possibilidades que se abrem. O mundo é muito mais amplo. E ele fica disponível aqui na ponta dos nossos dedos quase que o tempo todo. Claro que sempre com a ressalva de que tudo depende do serviço de infraestrutura que a gente tem. Mas é muito mais fácil hoje em dia. Eu concordo que fazer isso é um desafio; fazer alguma coisa que seja local e que ganha o mundo dessa maneira tão exponencial é uma coisa difícil. Mas, ao mesmo tempo, eu acho que a gente vive num mundo que tem tantas trocas de experiência. Nossa vida hoje é isso, viver essa troca intensa de experiência. E eu acho que essa local nesse mundo maior acaba tendo uma dimensão que as pessoas vão assimilando. E eu acredito que assimilam muito mais pelo lado da cultura e da identidade. São dois elementos, identidade e matriz cultural, que vão, talvez, ajudar nessa tradução, nessa leitura de alguma coisa que seja local, mas que esteja midiatizado.

Revista ALTERJOR

Grupo de Estudos Alterjor:Jornalismo Popular e Alternativo (ECA-USP)

Ano 10 Volume ol Edição $23 \quad$ Janeiro-Junho de 2021

Avenida Professor Lúcio Martins Rodriģues, 443, Cidade Universitária, São Paulo, CEP: 05508-020 


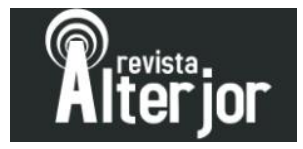

Mara e Edgard: É a segunda vez que você fala em identidade e cultura. Retomando um pouco os exemplos das fronteiras e dos processos migratórios que comentamos, envolvendo os gaúchos, por exemplo, como que a gente pode compreender os processos de assimilação cultural?

Sonia: Os gaúchos já estão lá em Mato Grosso há muito tempo. Eu tenho amigos cujos avós chegaram de carro de boi em Mato Grosso via Argentina. Por causa do rio e da falta de estrada, tinha que ir por onde era seco para a comitiva toda chegar a Mato Grosso. Ontem, eu estava conversando com um aluno da UnB. Ele é de Natal e estuda na UnB. Ele está fazendo uma disciplina de audiovisual e, lá pelas tantas, ele estava perguntando da minha audição - era sobre rádio - o que eu ouvia. E conversando com ele, eu lembrei que, nos meus 10, 12 anos, eu ouvia no meu rádio de pilha - que era muito bacana porque eu carregava para cima e para baixo - a rádio Guaíba de Porto Alegre, e eu estava em Campo Grande. Isso era nos anos 1960. Então você vê a cultura e essa "invasão", digamos assim, gaúcha; ela vinha com as pessoas, mas vinha também pela mídia, pelos meios de comunicação; naquele momento, pela mídia rádio. Numa boa parte da minha infância e adolescência, eu ficava ouvindo o noticiário do meio dia até dar a hora do almoço, mas era a rádio Guaíba de Porto Alegre. Então, nessa região, que hoje é Mato Grosso do Sul, mas quando eu nasci era Mato Grosso, a questão da fronteira é muito forte. A gente fala em guarani porque aprende quando é criança. Minha mãe dizia que a primeira música que manifestei algum tipo de reação foi Recuerdos de Ypacarai. Então, tem a fronteira física, mas a gente tem essa convivência que é muito legal e muito mais intensa. Eu acho que, no caso de Mato Grosso do Sul - e eu estava em Campo Grande -, também há essa troca com o Paraguai e, um pouco menos, com a Bolívia, porque é muito distante. Mas a questão fronteiriça é muito evidente na cultura e nos hábitos também; todo mundo toma tereré. Eu tomo chimarrão, mas tereré é mais popular até porque é uma região mais quente. Enfim, essa convivência cultural está no cotidiano das pessoas e na identificação também.

Revista AL TERJOR

Grupo de Estudos Alterjor: Jornalismo Popular e Alternativo (ECA-USP)

Ano 10 Volume ol Edição 23 Janeiro-Junho de 2021

Avenida Professor Lúcio Martins Rodrig̉ues, 443, Cidade Universitária, São Paulo, CEP: 05508-020 


\section{ARerior}

Mara e Edgard: Retomando a questão das escalas, como a demanda por pautas locais que não são contempladas na produção da mídia central, na imprensa nacional, tem aparecido nessas pesquisas, nesses olhares do GP de Geografias? Como você percebe isso?

Sonia: Eu acho que também é importante falar da perspectiva. Falando a partir de uma metrópole, a partir das grandes cidades, das capitais, a gente pode considerar o seguinte: a gente tem uma mídia local, que é essa mídia tradicional, e esses outros tipos de manifestações de mídia, como o jornalismo das periferias, que eu considero uma mídia hiperlocal, porque você está falando do bairro. O Martín-Barbero falava do bairro que é esse lugar de expressão da cultura de uma comunidade. Nos espaços urbanos maiores, e pensando em termos de escalas, eu acredito que a gente possa falar de uma mídia local. Se a gente está numa cidade, como Rio de Janeiro e São Paulo, por exemplo, essa escala muitas vezes é nacional, porque ultrapassa os limites territoriais do estado e da própria região.

A mídia hiperlocal é aquela cujo grande objetivo de quem a produz é ser reconhecido pelas pessoas do lugar onde você mora. E lugar é diferente de local. A Jacqueline Deolindo acompanhou as aulas de Geografias da Comunicação e trouxe um texto (DEOLINDO; ZANI; RIBEIRO, 2019), que ela apresentou ano passado no GP da Intercom, sobre o lugar; as concepções e as noções do conceito de lugar. Então, essa questão do lugar eu acho que é muito interessante. E a gente volta sempre para a mesma coisa, né, Edgard, que é o reconhecimento e a identificação.

Mara e Edgard: Na pesquisa sobre o Jornalismo das Periferias em São Paulo (ROVIDA, 2020) foi aparecendo uma dificuldade muito grande de classificação do tipo de comunicação produzida por essas iniciativas, com base em conceitos tradicionais como mídia alternativa, local, comunitária etc. Eles atuam a partir da seguinte perspectiva: 'eu falo da cidade como um todo e de tudo que diz respeito à vida na cidade, mas com o diferencial de trabalhar pautas a partir da perspectiva deste lugar'.

Revista ALTERJOR

Grupo de Estudos Alterjor:Jornalismo Popular e Alternativo (ECA-USP)

Ano 10 Volume ol Edição $23 \quad$ Janeiro-Junho de 2021

Avenida Professor Lúcio Martins Rodriggues, 443, Cidade Universitária, São Paulo, CEP: 05508-020 


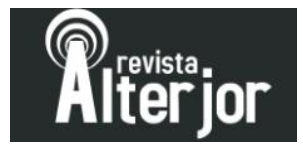

Então não necessariamente se fala do lugar para o lugar, mas se falo a partir do lugar. Como é que a gente se encaixa na discussão de escala nessa perspectiva?

Sonia Virginia Moreira: Eu acho que é uma mistura dessa revolução que você citou, porque, quando eu estava lendo as anotações que você fez, do que a gente podia conversar, essa questão do jornalismo da periferia me trouxe muito a lembrança do jornalismo comunitário, das mídias comunitárias. Eu acho que é uma evolução. E o diferencial, talvez, esteja nisso que você estava perguntando antes sobre o universo digital. Talvez você possa fazer uma distinção entre o que seja da periferia e o que seja comunitário, mas estamos falando das mesmas bases. Se nós formos pensar e colocar numa balança, quais as diferenças do jornalismo comunitário para o jornalismo da periferia? Talvez, o jornalismo comunitário estivesse mais voltado para dentro, e o jornalismo da periferia talvez seja isso, você também está voltado para fora. Então você fala do lugar e não para o lugar, mas você fazer as duas coisas também. Você fala do lugar para o lugar, mas fala para fora também. Então acho que essa pode ser uma evolução, em que, talvez, o comunitário estivesse voltado muito mais para a comunidade em que estava inserido até por conta do momento e hoje há uma abertura. Mas você continua pesquisando, então você vai falar para mim.

Mara e Edgard: Ainda nessa discussão, além do universo digital, como já foi trabalhado, existe também a questão da profissionalização dos produtores dessa comunicação das periferias. O jornalismo comunitário, a comunicação comunitária, prescindia de uma profissionalização. Você tinha as próprias lideranças dos movimentos sociais à frente da produção dessa comunicação. O jornalismo das periferias traz essa outra dimensão da profissionalização que parece, inclusive, atrelada ao desenvolvimento e ampliação de políticas públicas de acesso ao ensino superior no Brasil, anotadas na primeira metade dos anos 2000. Essa constatação da pesquisa sobre as iniciativas de São Paulo também tem sido observada em outros estudos contemporâneos. Então essa parece ser uma direção interessante para a gente pensar como o local se fortalece com a profissionalização do jornalismo.

Revista AL TERJOR

Grupo de Estudos Alterjor:Jornalismo Popular e Alternativo (ECA-USP)

Ano 10 Volume ol Edição $23 \quad$ Janeiro-Junho de 2021

Avenida Professor Lúcio Martins Rodriggues, 443, Cidade Universitária, São Paulo, CEP: 05508-020 
Sonia: É isso. Muito bom e muito real. Tudo a ver no que está dizendo, Edgard. E quando você estava falando no que era, aquele momento do comunitário com os movimentos sociais, eu me lembrei - coisas que vem pela memória nas conversas - que a gente chegou a fazer na UERJ, na década de 80, o inicial do que seria a rede UERJ de comunicação popular. Olha que coisa. E começamos a dar aula de como fazer jornal, de como fazer um programa de rádio para o pessoal que era dos movimentos sociais e de bairro, com Nilópolis, Nova Iguaçu, Queimados. E eles iam para a universidade e tinham aulas de jornalismo. Então acho que isso é bem interessante para compor com o que você está dizendo. As pessoas não tinham esse acesso antes e passaram a ter. Então com certeza isso é um elemento que vai evidenciar e mudar bastante esse panorama. A própria percepção e a forma de fazer jornalismo.

Mara e Edgard: Isso faz lembrar os projetos de educomunicação, muito fortes na Escola de Comunicações e Artes da USP, com o professor Ismar de Oliveira. Mas, paralelamente, as iniciativas de jornalismo das periferias também têm promovido oficinas e outras ações educomunicativas por conta própria.

Sonia: Novamente a gente volta para a mesma questão que é a do mundo digital. O que essas ferramentas do mundo digital permitem você fazer; você produzir, porque antes era muito mais difícil. Então você precisava do mediador. E o mediador nesse caso estava dentro da universidade, não é? E hoje essa mediação é dispensada. Você tem a sua realidade; você tem a vontade de fazer alguma coisa; você tem a necessidade de falar sobre determinados temas porque é sempre isso, a abordagem é sempre uma abordagem de temas que você não encontra em nenhum outro lugar, de uma realidade muito específica e muito próxima. Então você vai à luta e vai produzir sobre isso.

Mara e Edgard: Nesse sentido, dá para falar que o digital já tem uma marca nessa descentralização de quem produz a comunicação? Ainda que esse alcance enfrente outras limitações que a gente já comentou aqui. 


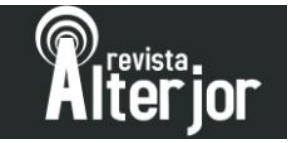

Sonia: Descentralização, e eu diria até de democratização mesmo apesar de todas as dificuldades, apesar das questões de infraestrutura. Mas eu acho que permite, cria a possibilidade. A gente está aqui conversando, estamos nos vendo [a entrevista foi feita por videoconferência], cada um num lugar deste país que tem este tamanho continental. O seu celular pode ser a sua câmera, você pode filmar e você não está interessado na qualidade técnica, mas no registro, no registro do seu lugar, do seu espaço, do tema que quer tratar.

Mara e Edgard: Ainda sobre essa questão do digital que tem muitas implicações. Além da questão da descentralização, da acessibilidade e da democratização, há também a dimensão das big techs, que hoje funcionam como grandes monopólios. De uma certa maneira, as big techs conformam quem vai ter acesso à comunicação, por exemplo, se a gente pensar na utilização dos algoritmos em redes sociais. Então existe uma interferência, um tipo de mediação. Parece que a gente sai do processo de monopolização da comunicação representada pelas grandes redes nacionais e cai em outro processo de oligopolização representado pelas big techs. Como é que fica o local nisso tudo?

Sonia: Essa questão é muito relevante e é outra coisa que eu também tinha até anotado para falar, porque a gente não pode deixar de fora dessas considerações a questão das plataformas. Tem uma sigla, GAFA, que é Google, Apple, Facebook e Amazon, que dominam o mercado. E quando você trata do jornalismo das periferias, por exemplo, muitas vezes a produção é distribuída no Facebook ou pelo WhatsApp, que é muito usado também, e é do Facebook. Então isso que a gente está fazendo aqui [durante a entrevista], está se reunindo numa plataforma que é do Google. Isso me impressiona muito porque, de alguma maneira, isso também está registrado em algum lugar. Todas as aulas desse semestre que foram feitas pelo Google Meet, elas provavelmente estão lá guardadas numa nuvem do tamanho de alguma coisa. Muitas vezes a gente não pensa nesse fenômeno. Eu tenho ficado, particularmente, incomodada com isso. Agora

\footnotetext{
Revista ALTERJOR

Grupo de Estudos Alterjor:Jornalismo Popular e Alternativo (ECA-USP)

Ano 10 Volume ol Edição 23 Janeiro-Junho de 202l

Avenida Professor Lúcio Martins Rodriģues, 443, Cidade Universitária, São Paulo, CEP: 05508-020
} 


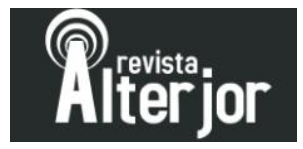

também a questão do Google e o processo penal que eles estão sofrendo nos Estados Unidos por causa do sistema de buscas. Mas o Google é muito mais do que um sistema de buscas. Também me interessa essa questão de propriedade de mídia, dessa coisa de grandes monopólios. E isso das plataformas, eu acho que é uma coisa que a gente precisa prestar muita atenção. Até porque isso que nós identificamos como um jornalismo local, uma produção local, ela está sendo produzida nessas plataformas. E que tipo de uso também pode ser feito a partir disso? Talvez, voltando para aquela sua questão de dominação, eu acho que esse é o nosso estado dominador deste momento, esse das plataformas digitais, porque todo mundo tem essa facilidade, todo mundo usa e produz ou faz esse tipo de encontro como estamos fazendo aqui e, na verdade, estamos usando grandes empresas, grandes grupos. Na UFRJ, por exemplo, adotou-se uma ferramenta do Google para as aulas. Então eu penso assim 'que bom, que legal, facilita a vida, você cria turmas, você tem e-mails específicos, você só entra naquela aula se tiver aquele e-mail que é a sua identidade, para você assistir aquela aula'. Mas, olha, eu também acho que não tem só um lado da tecnologia. Tem esse outro lado que é meio cruel.

Mara e Edgard: Essa profissionalização do jornalismo das periferias pressupõe também a produção de um material de melhor qualidade. Por isso, as grandes empresas de comunicação, de jornalismo começam a olhar com interesse para esse material, principalmente, a partir de uma capilaridade que elas não têm, mas as iniciativas das periferias possuem. Começa-se a anotar uma aproximação entre esse jornalismo das periferias e o jornalismo mainstream. Como você entende essa relação?

Sonia: É uma aproximação e é importante ter consciência disso. Tem uma outra coisa que é fundamental nisso que é a informação. O que é informação e como essa informação é trabalhada. Tudo bem que você tem um grupo hoje de pessoas que não necessariamente passou pela universidade, então não tem uma formação; ou tem um grupo que tem essa formação e entra nesse mundo de produção digital, de conteúdo, de

Revista ALTERJOR

Grupo de Estudos Alterjor: Jornalismo Popular e Alternativo (ECA-USP)

Ano 10 Volume Ol Edição 23 Janeiro-Junho de 202l

Avenida Professor Lúcio Martins Rodrig̉ues, 443, Cidade Universitária, São Paulo, CEP: 05508-020 


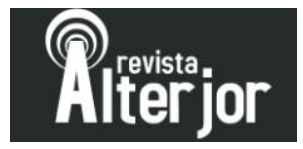

notícia, que eu acho que é uma forma muito democrática de você trabalhar; mas eu também fico com uma pulga atrás da orelha nessa questão da qualidade da informação. Então, o que é apurado? Tudo isso que circula, o uso das fontes. Eu sempre penso muito no Chaparro que tem um trabalho tão bom e fundamental sobre uso das fontes no jornalismo. E isso é uma coisa que me deixa assim às vezes preocupada. Eu estou falando a segunda coisa que eu não quero parecer pessimista não. A primeira foi essa questão da informação.

Mas a verdade aqui é que estou fazendo um brainstorming, porque acho que são todos temas que a gente tem que trazer para dentro das universidades, para dentro dos cursos, e para a sala de aula também. Então, pelo lado de quem produz, eu acho uma coisa muito legal, porque você tem um espaço muito maior de circulação. E junto com a circulação vem o reconhecimento também daquilo que você está produzindo e ele tem qualidade, o conteúdo daquele material tem qualidade. Mas, eu fico um pouco mexida, não sei se atordoada é uma palavra muito forte, porque junto com isso tudo a gente tem que ter sempre na frente da gente a questão da qualidade daquilo que é produzido, como é produzido e, depois, quando tem esse tipo de circulação, o tipo de uso que se faz também desse material pela mídia convencional.

Você tinha falado dessa coisa da descentralização no jornalismo das periferias e eu acho que hoje a gente vive esse mundo de contraste, porque a gente tem essa descentralização de produção, e a gente também tem uma centralização quando a gente pensa, por exemplo, na produção de streaming. Quem está produzindo streaming hoje no Brasil? $\mathrm{Eu}$ estou pensando nisso porque tem uma pesquisadora de pós-doc que estou acompanhando, a Ana Paula Ladeira Costa, que está trabalhando com a Netflix e esse sistema de produção no Brasil; de como essa produção brasileira está acontecendo aqui e sendo distribuída pra fora, e como essa produção que é de fora circula aqui dentro via Netflix. Então no fundo a gente fica falando das mesmas coisas. O que é isso que a gente produz para dentro, o que produz para fora, e o que vem de fora e circula aqui dentro do nosso mercado. Mas acho que também é uma coisa interessante. E você fala disso no seu livro, Mara, é pensar sempre essas questões de diversidade. Quando a gente fala de jornalismo, para mim, a diversidade é sempre de fontes. E a pluralidade é sempre 


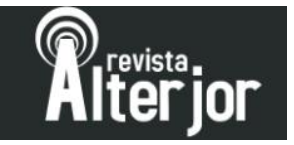

de vozes. Então essa questão de diversidade e pluralidade é um elemento que, talvez, ele precisasse ter uma forma ou uma consistência que fosse mais coordenada dentro da própria estrutura dos cursos de jornalismo. Mas aí já é outra coisa, um outro 'pitaco'.

Mara e Edgard: Algumas das iniciativas que vem sendo enquadradas nessa nova onda do jornalismo independente se autodefinem a partir de questões do próprio jornalismo, como aqueles que indicam como objetivo a produção de reportagens de profundidade. Assim, nem sempre o lugar é esse ponto de apoio. Então existe mais esse aspecto para dificultar uma possível categorização ou classificação.

Sonia: Mas eu acho que é isso, que é o que o te move, Edgard. O que afinal é isso que a gente pode identificar como o local? Sei lá, eu acho que a gente vai ter que trabalhar sempre a questão da proximidade mesmo. E junto com a proximidade vem isso, vem identidade também. Eu acho que são elementos que vão ajudar a formar isso que a gente entende como o local, porque, talvez, o local também seja uma forma de se reconhecer, de reconhecimento, quase um espelho. Não é fácil. O Andrew Herod (2011) tem esse livro que eu acho muito importante que fala das escalas, e ele na verdade começa o livro com o corpo. Então, essa é a primeira escala. E eu acho que é essa escala inserida na realidade; a escala do corpo e a forma de inserção dentro de uma dada realidade. E aí um pouco do que eu estava falando de proximidade é o que vai definir também o que é o local. Mas o corpo é o ponto de partida.

Mara e Edgard: Você acabou de tocar num ponto central. Os jornalistas falam muito da periferia, numa perspectiva que se aproxima da ideia de Milton Santos de um território produzido por sujeitos. Então, no fim das contas a gente não está falando da periferia, mas dos sujeitos da periferia. Então, esse corpo periférico, ainda que esteja transitando em outros lugares, ele ainda é uma periferia.

Sonia: E essa questão do corpo, eu acho uma chave; e uma chave muito importante para os nossos estudos de comunicação e uso dos elementos da Geografia. E outra coisa que

\footnotetext{
Revista ALTERJOR

Grupo de Estudos Alterjor: Jornalismo Popular e Alternativo (ECA-USP)

Ano 10 Volume Ol Edição 23 Janeiro-Junho de 202l

Avenida Professor Lúcio Martins Rodrig̉ues, 443, Cidade Universitária, São Paulo, CEP: 05508-020
} 


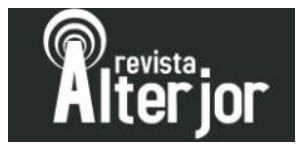

o Milton Santos também diz, e que eu acho muito real e muito bonito - principalmente pensando em nós, no Brasil -, é o território usado; porque o território usado são as pessoas no território. Falando disso, falando de corpo e trazendo um pouquinho do que eu sei sobre território e territorialidades, eu acho que territorialidade na verdade é isso, é a maneira que você usa o território, o que você faz nesse território. Tem a expressão do Milton Santos, território usado (SANTOS; SILVEIRA, 2001; SANTOS, 1999), que ele traz num trecho do texto "Dinheiro e território", para mim define muita coisa. Define também o que é território na pesquisa de regiões de sombra. E eu acho que fazendo essa transposição do jornalismo das periferias é esse território usado também do jornalista. $\mathrm{O}$ uso do jornalismo no território.

Mara e Edgard: A última pergunta. Como é que a gente está levando todas essas questões para a formação dos comunicadores, nas escolas de comunicação?

Sonia: Eu falei muito do meu lugar da Geografia pensando a Comunicação. Eu acho que ainda precisa de uma atenção maior da Geografia e de tudo que ela possibilita como campo de estudo e como referência para nós na comunicação. Por exemplo, tudo o que a gente está conversando aqui, lugar, território, local, urbano. E a gente nem entrou na ideia de espaço, porque é uma coisa muito complicada. Eu acho que nós temos, de alguma maneira, que fazer essa aproximação de uma forma mais frequente, porque ainda existe - e é importante - um predomínio da História da Comunicação e menos da Geografia. As duas disciplinas, as duas áreas, se integram de uma maneira tão bonita, que eu acho que é fundamental a gente ter mais elementos da Geografia no ensino da Comunicação, no ensino do Jornalismo.

Quando eu dei a disciplina de História do Jornalismo, em 2017, eu fiz uma coisa que é uma brincadeira, mas é essa relação com o objeto e com os temas que a gente gosta. Eu fiz uma aproximação com a Geografia porque é importante trazer para a vida deles [dos alunos]. Por exemplo, quando a gente mora no Rio de Janeiro, é preciso ter noção de que se está numa cidade que foi capital da República. E aí vem a aproximação histórica e tudo isso; eles têm de ter noção desse lugar onde eles estão. Então teve duas coisas

Revista AL TERJOR

Grupo de Estudos Alterjor: Jornalismo Popular e Alternativo (ECA-USP)

Ano 10 Volume Ol Edição 23 Janeiro-Junho de 202l

Avenida Professor Lúcio Martins Rodrig̉ues, 443, Cidade Universitária, São Paulo, CEP: 05508-020 


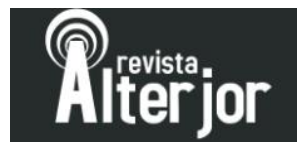

interessantes. Primeiro eu os levei para visitar os arquivos: o Arquivo da Cidade, o Arquivo Nacional e a Biblioteca Nacional. Eles mesmos pediram para ir ao Itamaraty, porque tinha gente que gostava deste mundo das relações exteriores. E aí todas as pessoas que eu entrei em contato foram muito solícitas. Foi uma maravilha visitar os acervos com eles. Pegar na mão a primeira edição do Correio Braziliense. Tem no Arquivo Nacional. O Arquivo Nacional tem coisas lindíssimas. E eu sempre achei que o Correio Braziliense fosse um jornal grande, um standard. E ele era do tamanho de um livro pequeno. Eu não vou falar dimensões para não me arriscar a falar bobagens, mas era. Então eles estavam ali tendo uma aula de História ao vivo, com os objetos. Um aspecto era esse, conhecer os acervos, então a gente está andando pela cidade, que é o local, é um elemento da Geografia, e conhecendo a história, a história do jornalismo; vendo mapas no Arquivo da Cidade. O Arquivo da Cidade tem coisas maravilhosas, como o desenho do centro da cidade, da avenida Presidente Vargas, por exemplo, e ruas ali perpendiculares, com os desenhos dos prédios, porque era uma forma de evitar que as pessoas não pagassem a conta de energia - era da Light - do jeito que tinham que pagar, porque eles falavam 'ah, aqui só tem um andar'; não, se o prédio tinha dois andares, a sua conta tinha que ser maior. Enfim, e é um mapa do tamanho de uma mesa, enorme, lindo. E é uma preciosidade que está aqui, no Arquivo da Cidade, na Biblioteca Nacional, que é um mundo maravilhoso.

E o outro aspecto foi também mostrar as aquarelas que os primeiros viajantes que chegaram ao Rio de Janeiro pintavam. Nas expedições sempre tinham os desenhistas. E eles desenhavam a cidade, desenhavam o entorno, as plantas, o espaço, as pedras, que é uma coisa maravilhosa. E tudo isso está no acervo da Biblioteca Nacional. Então você vê que História e Geografia se aproximam o tempo todo, e às vezes a gente meio que desfoca a Geografia. Então é só uma questão de ajuste, de foco. Você foca nas duas, em História e em Geografia. Às vezes mais em História, às vezes mais em Geografia, e vai mexendo assim essas ladies [as disciplinas].

Revista ALTERJOR

Grupo de Estudos Alterjor: Jornalismo Popular e Alternativo (ECA-USP)

Ano 10 Volume ol Edição 23 Janeiro-Junho de 2021

Avenida Professor Lúcio Martins Rodrig̉ues, 443, Cidade Universitária, São Paulo, CEP: 05508-020 


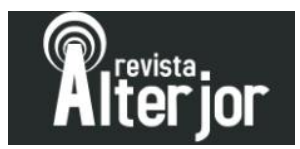

\section{REFERENNCIAS}

BRANDALISE, Roberta. A televisão brasileira nas fronteiras do Brasil com o Paraguai, a Argentina e o Uruguai - um estudo sobre como as representações televisivas participam da articulação das identidades culturais no cotidiano. $591 \mathrm{f}$. Tese (Doutorado em Interfaces Sociais da Comunicação). Universidade de São Paulo, USP, São Paulo, 2011.

DEOLINDO, Jaqueline; RIBEIRO, Anelise dos Santos; ZANI, Milena Firmino. Que lugar é esse? Da geografia humanista aos estudos de comunicação local. INTERCOM, $42^{\circ}$, Belém-PA. Anais: Intercom, 2019, p. 1-14.

HEROD, Andrew. Scale. London \& New York: Routledge, 2011

INNIS, H.A. O Viés da Comunicação. Petrópolis: Vozes, 2011.

INNIS, H.A. The Bias of Communication. Toronto: Toronto University Press, 2008.

INNIS, H.A. Empire and Communications. Lanham: Roman \& Littlefield Publishing Group, 2007.

FALKHEIMER, Jesper; JANSSON, André (eds). Geographies of Communication the spatial turn in Media Studies. Sweden: Nordicom, 2006.

MOREIRA, Sonia Virginia et al. (Orgs). 10 anos: o percurso do grupo de pesquisa Geografias da Comunicação no Brasil. São Paulo: Intercom, 2019.

ROVIDA, Mara. Jornalismo das periferias - o diálogo social solidário nas bordas urbanas. Curitiba: CRV, 2020.

SANTOS, Miton; SILVEIRA, Maria Laura. O Brasil - território e sociedade no início do século XXI. Rio de Janeiro: Record, 2001.

SANTOS, Miton. O dinheiro e o território. GEOgraphia, n. 1, 1999, p. 7-13.

Revista ALTERJOR

Grupo de Estudos Alterjor:Jornalismo Popular e Alternativo (ECA-USP)

Ano 10 Volume Ol Edição 23 Janeiro-Junho de 202l

Avenida Professor Lúcio Martins Rodrig̉ues, 443, Cidade Universitária, São Paulo, CEP: 05508-020 